\title{
PENGARUH CUSTOMER PERCEIVED VALUE, CUSTOMER SATISFACTION, DAN PRODUCT INNOVATION TERHADAP CUSTOMER LOYALTY (STUDI KASUS REBRANDING ALL NEW SOUR SALLY)
}

\author{
Faranita Amelia \\ Program Studi Magister Manajemen Universitas Tarumanagara \\ faranitamelia@gmail.com \\ Keni \\ Program Studi Magister Manajemen Universitas Tarumanagara
}

\begin{abstract}
This study aims to determine the success of All New Sour Sally rebranding in attracting customer loyalty, which loyalty is seen as one of the important criteria for companies to gain their competitive advantages. The research carries out by taking three independent variables, consisting of customer perceived value, customer satisfaction, and product innovation. This is a descriptive research by using questionnaire which distributed to 167 respondents in Jakarta area. Data was collected by using non probability sampling method. Multiple regression analysis used for data analysis by using SPSS version 23. The findings of the study prove the previous research that each of the three independent variables have significant effect to influence customer loyalty.
\end{abstract}

Abstrak : Penelitian ini bertujuan untuk mengetahui keberhasilan rebranding All New Sour Sally dalam menarik loyalitas konsumen, karena loyalitas dipandang sebagai salah satu kriteria penting bagi perusahaan untuk memperoleh keunggulan kompetitif. Penelitian dilakukan dengan mengambil tiga variabel bebas, yaitu terdiri dari customer perveived value, customer satisfaction, dan product innovation. Jenis penelitian yang dilakukan adalah penelitian deskriptif dengan menggunakan kuesioner yang disebarkan kepada 167 responden di Jakarta. Pengambilan data dilakukan dengan metode non probability sampling. Analisis data menggunakan analisis linear berganda dengan program SPSS versi 23. Hasil temuan penelitian membuktikan penelitian terdahulu bahwa ketiga variabel bebas yang diambil mempengaruhi secara signifikan terhadap loyalitas konsumen.

Keywords : Rebranding, customer perceived value, customer satisfaction, product innovation, customer loyalty

\section{PENDAHULUAN}

Dalam ketatnya persaingan pasar, produsen dituntut untuk berlomba-lomba mengadu kreativitasnya dalam memenangkan kompetisi. Hal ini menyebabkan brand tidak lagi hanya sebuah nama, melainkan sebuah identitas. Dalam proses berjalannya suatu brand, tidak menutup kemungkinan terjadinya proses rebranding. Aaker (1997) menyatakan bahwa merevitalisasi dan reposisi brand melalui modifikasi bertahap dari proposisi merek dan estetika pemasaran dapat dianggap sebagai hal yang alami dan perlu, sebagai bagian dari misi manajemen merek terhadap respon perubahan kondisi pasar. Rebranding inilah yang dilakukan oleh All New Sour Sally saat brand-nya harus menghadapi fase tren frozen yogurt yang mulai meredup. Dimulai dari mengubah pangsa pasar dari remaja perempuan ke pasar dewasa khususnya usia pekerja yang memiliki kehidupan lebih dinamis. Terdapat value berbeda dalam konsep barunya yang menyesuaikan dengan lifestyle. All New Sour Sally juga meluncurkan produk ikon baru yaitu varian Black Sakura dan varian cara penyajian berbeda dengan menggunakan cone es krim bernama Lykone. Strategi pemasaran dijalankan dengan lebih aktif dengan berbagai corporate activities untuk meningkatkan brand awareness.

Rebranding merupakan langkah besar dalam strategi perusahaan. Langkah ini bisa menjadi sebuah gagasan baik untuk menciptakan ekspektasi baru yang berpeluang atau meruntuhkan brand equity yang sudah diciptakan bertahun-tahun. Tolak ukur keberhasilan suatu brand tentunya tidak dapat dipisahkan dari pelanggan. Menurut Oliver (1990) loyalitas dipandang sebagai salah satu 
kriteria penting bagi perusahaan untuk memperoleh keunggulan kompetitif karena menentukan pembelian kembali pelanggan di masa depan.

Di salah satu prosesnya, customer loyalty dipengaruhi oleh kemampuan konsumen dalam mengevaluasi nilai (perceived value). Dalam penelitian Yang dan Peterson (2004) dinyatakan bahwa nilai yang dirasakan oleh pelanggan adalah salah satu pendorong utama loyalitas pelanggan.

Kepuasan pelanggan pun memiliki kontribusi dalam menentukan perilaku konsumen di masa mendatang untuk cenderung kembali mengonsumsi produk, yang lalu memicu loyalitasnya. Erevelles dan Young (1992) mengungkapkan bahwa satisfaction merupakan elemen pusat dan utama dari konsep pemasaran.

Aaker (1997) menyatakan bahwa tugas brand adalah membentuk image dengan memberikan perbedaan dengan produk lainnya dan melakukan penelitian untuk memaksimalkan keunikan produk. Lee (2011) menyatakan bahwa selain corporate image, price, dan product quality, terdapat product innovation yang juga mampu mempengaruhi customer loyalty.

Penelitian ini mengeksplorasi pengaruh customer perceived value, customer satisfaction, dan product innovation terhadap customer loyalty dalam rebranding All New Sour Sally.

\section{TELAAH KEPUSTAKAAN \\ Customer Perceived Value}

Pengertian customer perceived value menurut Kotler dan Keller (2016) bahwa "Customer perceived value is the difference between the perspective customer's evaluation of all benefits and all the costs of an offering and the perceived alternatives." Konsumen akan cenderung memilih produk yang memberikan value maksimum dengan biaya pengorbanan yang mimimum.

\section{Customer Satisfaction}

Penilaian kepuasan konsumen terhadap produk atau jasa didasari oleh reaksi psikologis konsumen terhadap evaluasi ekspektasi manfaat produk.. Kotler dan Keller (2016) mendefinisikan customer satisfaction sebagai "A person's feeling of pleasure or dissapointment resulting from comparing a product's perceived perfomance or outcome in relation to his or her expectations." Disimpulkan bahwa konsumen akan merasa puas bila harapan mereka terpenuhi dan merasa amat gembira bila harapan terlampaui.

\section{Product Innovation}

Inovasi merupakan bagian dari mekanisme perusahaan untuk beradaptasi dengan lingkungan yang dinamis. Inovasi terhadap perubahan faktor internal dan eksternal lingkungan perusahaan diperlukan untuk bersaing di kompetisi pasar. Schumpeter (1934) mengemukakan bahwa "Product innovation means making new products and offering new services, or adding new value to existing ones."

\section{Customer Loyalty}

Loyalitas pelanggan merupakan suatu hal yang penting bagi perusahaan karena pelanggan yang loyal akan mendatangkan keuntungan dari pembelian berulang. Griffin (2011) menyatakan bahwa "Customer loyalty can be described as a customer repurchase, buying between product lines and services, refer to others, and immunity against competitors."

\section{Kaitan antar Variabel}

- Kaitan antara customer perceive value dan customer loyalty

Yang dan Peterson (2004) meneliti bahwa ada pengaruh signifikan customer perceived value sebagai salah satu variabel yang mempengaruhi customer loyalty pengguna online store. Pemenuhan ekspektasi konsumen terhadap value yang diberikan berperan meningkatkan kekebalan konsumen terhadap brand competitor. Hasil serupa ditemukan dalam penelitian Javed (2017), dimana customer perceived value memiliki tingkat signifikansi tertinggi dibandingkan variabel independen lain yang mempengaruhi customer loyalty konsumen restoran lokal di Pakistan. Customer perceived value adalah dasar fundamental bagi kegiatan pemasaran suatu brand. Berdasarkan uraian tersebut, hipotesis penelitian $\left(\mathrm{H}_{1}\right)$ adalah:

$\mathrm{H}_{1}$ : Terdapat pengaruh positif pada customer perceived value terhadap customer loyalty. 
- Kaitan antara customer satisfaction dan customer loyalty

Dalam penelitian Bakti dan Sumaedi (2012), customer satisfaction berpengaruh positif terhadap customer loyalty pengguna perpustakaan. Kenyamanan dari servis akan membuat pengunjung puas dan memicu keinginan datang kembali ke perpustakaan. Penelitian Chang dan Wang (2010) menemukan nilai positif signifikan tertinggi pada variabel customer satisfaction dalam pengaruhnya terhadap customer loyalty bila dibandingkan dengan dua variabel lainnya yang digunakan dalam penelitian. Konsumen yang puas akan mengurangi kecenderungan untuk pindah ke pesaing sehingga meningkatkan sikap pembelian berulang di brand yang telah memuaskannya. dimana hal ini juga merupakan sikap dari konsumen yang loyal. Maka, ditarik hipotesis penelitian $\left(\mathrm{H}_{2}\right)$ adalah:

$\mathrm{H}_{2}$ : Terdapat pengaruh positif pada customer satisfaction terhadap customer loyalty.

- Kaitan antara product innovation dan customer loyalty

Penelitian Lee (2011) menunjukkan product innovation berpengaruh positif terhadap customer loyalty. Proses penanytian terhadap inovasi mempengaruhi konsumen untuk fokus pada perkembangan brand dan cenderung tidak memperhatikan brand lain. Kekebalan terhadap kompetitor ini merupakan salah satu bentuk loyalitas. Onojaefe (2017) menemukan pengaruh product innovation terhadap customer loyalty dapat menciptakan memori menyenangkan dalam benak konsumen yang kemudian membuat brand akan menjadi prioritas konsumen dibandingkan brand lain di kemudian hari. Berdasarkan uraian tersebut, hipotesis penelitian $\left(\mathrm{H}_{3}\right)$ adalah:

$\mathrm{H}_{3}$ : Terdapat pengaruh positif pada product innovation terhadap customer loyalty.

\section{METODOLOGI PENELITIAN}

Penelitian yang dilakukan adalah penelitian deskriptif cross-sectional. Data mengenai variabe; penelitian, antara lain: customer perceived value, customer satisfaction, product innovation, dan customer loyalty yang dikumpulkan pada waktu tertentu.

Populasi dalam penelitian adalah masyarakat Jakarta yang pernah mengonsumsi yogurt All New Sour Sally. Sampel penelitian sebanyak 200 responden. Dalam pengambilan sampel, metode yang digunakan adalah non probability sampling dengan teknik convenience sampling. Berdasarkan pengumpulan data, diketahui bahwa mayoritas responden adalah perempuan $(86,22 \%)$, berusia di atas 25 tahun (52,1\%), berprofesi sebagai karyawan (50,29\%), dan berdomisili di Jakarta Barat $(38,32 \%)$.

Untuk mengukur variabel penelitian, instrumen untuk masing-masing variabel diadaptasi dari penelitian terdahulu. Skala pengukuran (kecuali profil responden) diukur dengan skala likert yang terbagi menjadi 5, dimana nilai 1 mendeskripsikan sangat tidak setuju (STS) dan nilai 5 yang mendeskripsikan sangat setuju (SS). Dalam tabel 1 menunjukkan instrumen masing-masing variabel beserta sumbernya. Keseluruhan instrumen dilakukan analisis validitas dengan hasil corrected item total correlation berkisar dari 0,431 sampai dengan 0,796 . Nilai corrected item total correlation lebih besar dari nilai 0,3 menyatakan keseluruhan instrumen valid (Sugiyono, 2011). Sedangkan untuk analisis reliabilitias menunjukkan semua variabel penelitian memiliki nilai cronbach's alpha berkisar antara 0,767 sampai dengan 0,913. Nilai tersebut menunjukkan bahwa keseluruhan instrumen reliabel karena nilainya lebih besar dari 0,6 (Maholtra, 2009). 
Tabel 1. Variabel dan Pengukuran

\begin{tabular}{|l|c|c|}
\hline \multicolumn{1}{|c|}{ Variabel } & Item & Sumber \\
\hline $\begin{array}{l}\text { Variabel bebas: } \\
\text { Customer perceived value }\end{array}$ & 5 & Yang dan Peterson (2004) \\
$\begin{array}{l}\text { Customer satisfaction } \\
\text { Product innovation }\end{array}$ & 5 & Chuah, et al (2017) \\
\hline $\begin{array}{l}\text { Variabel terikat: } \\
\text { Customer loyalty }\end{array}$ & 5 & Ayanti dan Fontana (2011) \\
\hline
\end{tabular}

Penelitian dilakukan dengan menggunakan kuesioner yang disebar secara online melalui media Google Form. Analisis regresi berganda digunakan untuk mengetahui pengaruh masing-masing variabel bebas terhadap variabel terikat. Sebelumnya, uji asumsi seperti uji normalitas, uji multikolinearitas, dan uji heterokedastisitas telah dilakukan dan hasilnya menunjukkan bahwa semua uji asumsi terpenuhi dengan menggunakan taraf signifikansi $5 \%$.

\section{HASIL DAN PEMBAHASAN}

Tabel 2 menunjukkan hasil analisis data secara singkat. Berdasarkan tabel tersebut, diperoleh hasil bahwa keseluruhan variabel bebas secara positif mempengaruhi variabel terikat, yang juga membuktikan bahwa keseluruhan hipotesis diterima. Dari tabel tersebut juga ditunjukkan bahwa variabel customer satisfaction memiliki pengaruh terbesar dalam mempengaruhi customer loyalty dibandingkan dengan kedua variabel bebas lainnya.

Tabel 2. Hasil Pengujian Hipotesis

\begin{tabular}{|l|l|c|c|}
\hline \multicolumn{1}{|c|}{ Hipotesis } & Koefisien & Nilai t \\
\hline $\mathrm{H}_{1}$ & $\begin{array}{l}\text { Customer perceived value } \rightarrow \\
\text { customer loyalty }\end{array}$ & 0,275 & $0,001^{*}$ \\
\hline $\mathrm{H}_{2}$ & $\begin{array}{l}\text { Customer satisfaction } \rightarrow \\
\text { customer loyalty }\end{array}$ & 0,445 & $0,000^{*}$ \\
\hline $\mathrm{H}_{3}$ & $\begin{array}{l}\text { Product innovation } \rightarrow \text { customer } \\
\text { loyalty }\end{array}$ & 0,277 & $0,000^{*}$ \\
\hline
\end{tabular}

Hasil pengujian hipotesis $\mathrm{H}_{1}$ sesuai dengan penelitian sebelumnya oleh Yang dan Peterson (2004) bahwa tergenapinya perspektif evaluasi konsumen terhadap manfaat produk yang dibayarkan sepadan dengan biaya dapat membentuk kekebalan konsumen terhadap penawaran dari produk alternatif. Hasil ini juga terlihat dari total skor dalam kuesioner sebesar 65,9\% (551 dari 835 respon bernilai 4 dan 5 pada keseluruhan indikator customer perceived value) dan hasil evaluasi manfaat yang diharapkan dan dirasakan konsumen setelah mengonsumsi yogurt adalah sebesar 90,06\% (akumulasi dari persentase manfaat pencernaan lancar, merasa kenyang, segar, dan bahagia). Dengan demikian, data tersebut menunjukkan bahwa konsumen All New Sour Sally memberikan respon positif terhadap value yang ditawarkan brand dan dirasakan lebih baik dibandingkan kompetitor. Hal ini tentunya menjadi masukan bagi brand untuk dinamis mengetahui dinamika selera agar evaluasi value bisa dilakukan secara berkala.

Sementara untuk hasil pengujian hipotesis $\mathrm{H}_{2}$ serupa dengan penelitian Chang dan Wang (2010), dimana konsumen yang puas dengan evaluasinya saat mengonsumsi produk akan mengurangi kecenderungan untuk pindah ke brand lain. Data kuesioner sebesar 86,2\% menjawab mereka puas dengan pengalaman setiap kali membeli All New Sour Sally (sebanyak 144 dari 167 responden bernilai 4 dan 5 pada indikator keempat customer satisfaction). Survey pelanggan terhadap manfaat produk juga mendukung penyataan ini, dengan hasil sebesar 34,25\% mengatakan merasa bahagia setelah melakukan pembelian yogurt. Hal ini menunjukkan bahwa faktor-faktor terkecil yang 
mempengaruhi evaluasi pengalaman saat melakukan pembelian oleh pelanggan tentu tidak bisa lengah diacuhkan oleh perusahaan, mengingat fase kepuasan berulang yang dirasakan oleh pelanggan dapat mendatangkan pembelian berulang terhadap produk, yang merupakan salah satu ciri-ciri loyalitas. Dengan memperhatikan kepuasan konsumen tentunya menjadi strategi efektif karena pelanggan yang puas memiliki kemungkinan memberikan rekomendasi positif pada orang terdekatnya dan memperluas lingkup pemasaran brand.

Hasil pengujian hipotesis $\mathrm{H}_{3}$ sesuai dengan penelitian sebelumnya oleh Onojaefe (2017) bahwa inovasi yang ditawarkan All New Sour Sally, khususnya varian rasa Black Sakura (ditinjau dari jawaban pilihan sebesar 71,86\%) yang menjadi ciri khasnya berhasil membuat brand menjadi top of mind konsumen. Hasil ini juga didukung oleh jawaban dalam profil responden sebesar 48,96\% menyatakan motivasi pembelian yogurt dikarenakan menyukai varian yang ditawarkan oleh perusahaan. Dengan melihat hasil tersebut, maka dapat disimpulkan bahwa penting bagi perusahaan untuk menciptakan produk khas yang belum dimiliki kompetitor karena hal tersebut bisa menjadi alasan utama bagi pelanggan untuk melakukan pembelian berulang.

\section{KESIMPULAN DAN SARAN}

Hasil penelitian menunjukkan bahwa variabel customer perceived value, customer satisfaction, dan product innovation berpengaruh positif secara parsial terhadap customer loyalty All New Sour Sally di Jakarta. Value yang kuat dan dapat dimaksimalkan oleh brand mampu menciptakan sifat loyal konsumen. Tak terlupakan juga bahwa terpenuhinya harapan konsumen saat pembelian produk juga menjadi salah satu alasan konsumen kerap mengingat brand sehingga akan memilih brand sebagai prioritas utama saat ingin mengonsumsi produk. Eksistensi brand dengan terus berinovasi dari segala aspek dalam penjualan maupun pemasarannya turut membantu brand untuk tetap mempertahankan gaungnya dalam persaingan di pasar.

Dengan demikian, hasil penelitian juga memberikan saran agar perusahaan senantiasa meningkatkan customer perceived value, customer satisfaction, dan product innovation dalam kegiatan pemasarannya karena terbukti ketiganya secara positif mempengaruhi loyaltias pelanggan. Bagi penelitian selanjutnya, dihimbau untuk memperluas jangkauan wilayah penelitian dengan memilih area cabang All New Sour Sally lain di luar Jakarta dan memperluas pemilihan variabel. Pemilihan variabel lain yang bisa diteliti di antaranya adalah switching barriers, price, brand awareness, dan product quality.

\section{IMPLIKASI MANAJERIAL}

Berkaitan dengan hasil penelitian, maka dapat disampaikan beberapa implikasi manajerial yang bisa diterapkan oleh perusahaan. Meninjau dari hasil pengaruh positif oleh customer perceived value terhadap customer loyalty, maka dihimbau bahwa perusahaan senantiasa meningkatkan value dengan menjaga kestabilan kualitas produk sejalan dengan penetapan harga. Hal ini dilakukan agar pelanggan tetap merasa biaya yang dikeluarkannya sebanding dengan manfaat dan ekspektasi. Penetapan harga bisa dibarengi dengan penyelanggaraan promo menarik untuk menambah value dibandingkan kompetitor. Contohnya adalah evaluasi berkala terhadap bahan baku dari segi penyimpanan di inventory maupun outlet. Penetapan harga juga dapat dibarengi dengan penyelenggaraan promo menarik untuk menambah value produk dibandingkan dengan kompetitor.

Selain itu, perusahaan juga dianjurkan untuk tetap meningkatkan kualitas dalam menciptakan pengalaman saat pelanggan melakukan pembelian produk untuk mengurangi resiko timbul kekecewaan. Hal ini dikarenakan customer satisfaction ditunjukkan memiliki pengaruh positif dan peranan terbesar dalam mempengaruhi customer loyalty berdasarkan hasil penelitian. . Berbagai cara yang dapat dilakukan di antaranya adalah mengubah cara pelayanan dengan menyentuh kedekatan personal dengan konsumen, seperti menanyakan hobi yang bisa diselaraskan dengan pilihan topping yang sesuai atau melakukan kreasi terhadap penulisan nama konsumen di nota. Selain itu, bisa juga disiapkan tester yang dapat diaplikasikan untuk varian rasa yogurt dan sausnya dengan tujuan menambah refernsi konsumen untuk memilih varian yang ingin dibelinya.

Tak lupa juga dengan variabel product innovation, dimana perusahaan dihimbau untuk senantiasa berinovasi dalam segala aspek, seperti dalam packaging penyajian yogurt dan varian rasa sehingga meningkatkan ketertarikan pelanggan untuk datang membeli. Brand dapat melakukan inovasi seasonal yang disesuaikan dengan event, seperti rasa dan packaging khusus Valentine, Natal, atau Halloween. Inovasi juga dapat dilakukan dengan pemasaran yang aktif dan mengikuti tren. Salah 
satu ide pemasaran yang dapat diterapkan adalah dengan memanfaatkan hari raya Paskah, yaitu mencari telur tersembunyi di outlet All New Sour Sally dengan hadiah menarik yang dapat didapatkan oleh konsumen. Inovasi berkala bertujuan meningkatkan peluang brand untuk menjadi posisi top of mind apabila pelanggan ingin mengonsumsi yogurt.

\section{DAFTAR PUSTAKA}

Aaker, D.A. (1997). Managing Brand Equity: Capitalizing on the Value of Brand Name, The Free Press, New York, NY.

Bakti, I Gede Mahatma dan Sumaedi, Sik. (2012). The Role of Service Quality and Customer Satisfaction, A Case Study in Indonesia.

Chang, Hsin Hsin and Hsin-Wei Wang. (2010). The Moderating Effect of Customer Perceived Value on Online Shopping Behaviour.

Erevelles, S. and Young, C.E. (1992). “A comparison of current models of consumer satisfaction/ dissatisfaction", Journal of Consumer Satisfaction, Dissatisfaction and Complaining Behavior, Vol. 5, pp. 104-14.

Gay, L.R. and Diehl, P.L. (1992). Research Methods for Business and Management. Mc. Millan Publishing Company, New York.

Griffin, Jill. (2011). Customer Loyalty: Growing and Keeping Customers, Translation Dwi Kartini Yahya, publisher, Jakarta

Javed, Farheen. (2017). Customer Satisfaction and Customer Perceived Value and Its Impact on Customer Loyalty: The Mediatonal Role of Customer Relationship Management.

Kotler, Phillip, \& Kevin Lane Keller. (2016). Manajemen Pemasaran Jilid 1 (Edisi Ketiga Belas,). Jakarta : Penerbit Erlangga.

Lee, Jung-Wan. (2011). Critical Factors Promoting Customer Loyalty to Smartphone and Mobile Communications Service Providers.

Malhotra, N.K. (2009). Riset Pemasaran, Edisi keempat, Jilid 1. Jakarta: PT Indeks.

Oliver RL. (1999). Whence consumer loyalty? The Journal of Marketing 33-44.

Onojaefe, Darlington and Nicholas Nhepera. (2017). The Influence of Hotel Product Innovation on Customer Loyalty in Cape Town.

SCHUMPETER, J.A. (1934). The theory of economic development: an inquiry into profits, capital, credit, interest and the business cycle, Harvard Economic Studies, Vol. 46, Har- vard College, Cambridge, MA.

Sugiyono. (2011). Metode Penelitian Kuantitatif, Kualitatif dan R\&D. Bandung: Afabeta

Yang, Zhilin and Robin T. Peterson. (2004). Customer Perceived Value, Satisfaction, and Loyalty: The Role of Switching Costs.

Costs. 
